\title{
Santos Juliá, La Transición. Historia de una política española (1937- 2017). Madrid: Galaxia Gutenberg, 2017, 656 págs.
}

Ríos de tinta han corrido sobre la transición a la democracia, "ese muerto con buena salud" al que aludía el sociólogo Juan Linz y que se ha erigido, no solo como un punto axial de la historia contemporánea de España, sino también como todo un fenómeno editorial. No es ajeno a ello Santos Juliá, cuya dilatada carrera historiográfica lo convierte en voz autorizada para plasmar sus inquietudes intelectuales sobre un proceso que, pese al transcurrir de las décadas, goza de rigurosa actualidad.

En su escrito Juliá nos propone un periplo cronológico por la contemporaneidad española para mostrarnos que, a su juicio, la Transición, en contra de lo que se pudiera pensar, no es una etapa que deba ser enmarcada en los límites que tradicionalmente se le han otorgado, ya que no podría ser desligada la consumación del proceso de todas esas décadas de largas negociaciones y confrontación de proyectos entre posicionamientos ideológicos ya no distintos, también antagónicos, y cuyos productos serían nociones que cobraron vital protagonismo en los años setenta: amnistía, el reconocimiento de las libertades civiles, la resolución del conflicto territorial, etc. En definitiva, realidades resultantes del propio aprendizaje democrático de las figuras políticas y las numerosas organizaciones, tanto del interior como del exilio, que vendrían a paliar esa suerte de "mito de Sísifo" que parecía caracterizar la idiosincrasia de España.

Las reiteradas alusiones a significantes de tal calibre como "democracia" o el propio término de "transición" coparon no solo las mentes de los actores políticos de cada década, sino también sus proyectos, todos ellos, además, fuertemente influidos por el devenir de la política internacional, que planteaba la pareidolia de una rauda caída de la dictadura franquista. Pese a la innegable existencia de las citadas realidades, cabe preguntarse hasta qué punto estos significantes se mantuvieron inertes hasta los albores de la llamada "década prodigiosa", sobre todo si tenemos en cuenta el cariz que tomaron los proyectos democráticos de posguerra y la inserción de estas lógicas en el desarrollo de la Guerra Fría. Esta sea, quizá, la tarea pendiente de la obra de Santos Juliá.

Con una estructura cronológica bien definida, se atisban tres partes diferenciadas cuyas particularidades son dignas de mención: una inicial, en la que se acomete viaje desde las postrimerías de la guerra civil hasta la muerte de Franco; en segundo lugar, la vorágine del proceso; finalmente, y con suma probabilidad la más novedosa, una parte dedicada a la travesía política desde la llegada del Partido Socialista Obrero Español a la Moncloa en 1982 hasta la más rabiosa actualidad, con la eclosión de relatos escépticos en el seno de la organización política Podemos, nacida al calor de la crisis políticoeconómica y deudora de movimientos como el 15-M.

En el primero de los ejes que conforman este escrito Santos Juliá parte desde la propia experiencia bélica, en la que la triada de "paz, piedad y perdón" ambicionada por Manuel Azaña parecía poner la piedra angular de proyectos venideros. De esta manera, el historiador se sumerge en los grandes debates acometidos por figuras de diversa genealogía intelectual, como Indalecio Prieto, Santiago Carrillo o José María Gil-Robles, jalonados por el propio devenir de una dictadura que de provisional parecía tener poco. Sorprende la capacidad de adaptación de las diferentes cosmovisiones políticas a un 
entorno tan desfavorable, pues los vaivenes de la política internacional y la difícil conexión entre el exilio y el interior marcaron enormemente los posicionamientos. Esta será una de las realidades que, como señala el autor, intervino en la fluctuación de los diferentes designios.

Si la victoria aliada había dado cierto aliento a los republicanos, el paso de los años acabó por difuminar su proyecto en favor del monárquico que, como se muestra, no escatimó en conflictos con el aparato del franquismo en pos del retorno de un Borbón al trono español. A su vez, como vemos, el acercamiento a Europa pretendido por figuras como Salvador de Madariaga parecía, nuevamente, tornarse la solución a una España sobre la que caía la losa de erigirse, según el dramaturgo Ramón María del Valle-Inclán, "en la deformación grotesca de la civilización europea".

A lo largo de esta parte cobran relevancia sendos hitos distinguidos por el autor: el pacto de San Juan de la Luz de 1948, la revuelta universitaria de 1956 y el IV Congreso del Movimiento Europeo de 1962 (denominado de forma peyorativa por el diario falangista Arriba como el Contubernio de Múnich). Si en el primero de ellos existió un precoz acercamiento entre monárquicos y socialistas y en el segundo atendemos a la petición del Partido Comunista de España de suprimir esa lógica dicotómica entre "vencedores y vencidos" en pos de la "reconciliación nacional", en Múnich se habría representado el afán, en palabras de Salvador de Madariaga, de "cerrar definitivamente la guerra civil", un acontecimiento en el que Santos Juliá identifica las bases de lo que acabaría por consumarse más de una década después.

En la segunda de las partes que conforma el escrito, Juliá se detiene en la tríada que pondría el broche al proceso transicional, reivindicado en las manifestaciones populares: "libertad, amnistía y estatuto de autonomía".

En lo que se refiere al primero de citados términos, vislumbramos cómo discurrió la Transición, el fracaso de aquellos que siguieron con la óptica de 1936 en sus proyectos, las dificultades existentes para tejer un marco democrático después de cuarenta años de dictadura y las reivindicaciones de estudiantes, sindicatos, asociaciones de vecinos, etc., que se convertirían, según el historiador ferrolano, en el perfecto ejemplo del "aprendizaje democrático", idea que ya había postulado junto a José Carlos Mainer en El aprendizaje de la libertad.

Seguidamente, la amnistía cobra un papel vertebral en la obra pues sus ecos llegarían hasta nuestros días. Debemos recordar que esta protagonizaba ya, en los últimos estertores de la guerra, el décimo tercer punto del presidente del Consejo de Ministros Juan Negrín. Santos Juliá nos relata cómo se urdió la Ley de Amnistía de 1977, los vericuetos a los que se vio sometida y la trascendencia que poseería los actos violentos de diferentes formaciones terroristas como ETA ("País Vasco y Libertad"), los Guerrilleros de Cristo Rey, el FRAP (Frente Revolucionario Antifascista y Patriota) o los GRAPO (Grupo Revolucionario Antifascista Primero de Octubre). No obstante, pese a su mención, se requiere mayor profundidad en esta última cuestión, pues le otorga gran peso a la banda vasca sin recalar ya no solo en otros grupos terroristas, sino en la violencia parapolicial, cuyo estudio va ganando enteros en los acercamientos históricos a esta etapa. 
Para cerrar esta triada, Santos Juliá muestra las enormes dificultades existentes para organizar el marco territorial en el que, además, resonaban los ecos de veleidades pretéritas que no apaciguaban los nervios de unas Fuerzas Armadas que habían ocupado un lugar central durante el franquismo. De esta manera, el tejido territorial y los diferentes proyectos en los territorios periféricos estuvieron estrechamente ligados a debates de gran convulsión en el que ideas como la nación o el legado republicano tuvieron un protagonismo fundamental.

Clausura este bloque el célebre "desencanto". Este concepto tomado del documental de Jaime Chávarri sobre la familia Panero, alude a la zozobra de todas esas esperanzas vertidas sobre el proceso procedente desde diversos sectores ideológicos y que fue coetánea a este, con El País como gran artífice, según el historiador. No es casualidad carente de significado que le dedique un apartado a esta idea: en la actualidad, la crítica más férrea a la etapa transicional bebe de los efluvios de este desencanto, a la que él mismo le dedica, como veremos, apartados venideros en el escrito.

Ya en la tercera de las partes señaladas, Santos Juliá conjuga el desarrollo de su oficio con un análisis muy similar al que plasma con asiduidad en numerosos medios de comunicación. Debido a ello, sigue esa máxima gramsciana de "odiar al indiferente" y se posiciona, de forma tajante, contra lo que considera irregulares usos políticos de la Transición. He ahí su señalamiento a las pugnas políticas de la década de los noventa como fundacionales, en las que el pasado se habría tornado una efectiva arma arrojadiza entre los principales púgiles del arco parlamentario. Desde el célebre spot del dóberman del PSOE hasta la promulgación de la Ley 52/2007 (denominada comúnmente como "Ley de Memoria Histórica"), Juliá muestra los manejos instrumentales a los que se habría visto sometido el uso público de la historia.

Es polémica su visión sobre la citada ley, puesto que apela a la necesidad de escudriñar en "las memorias", cargadas siempre de gran conflictividad, y no en una memoria única, con el objetivo de integrar el reconocimiento moral de todas las víctimas del conflicto bélico y de la posterior dictadura. Por esta razón, apuesta por favorecer el acceso al conocimiento y al debate, desdeñar el maniqueísmo proveniente de la actividad política o desechar lo que considera tópicos manidos (amnesia, pactos de silencio...), todo ello en detrimento de relatos cáusticos o balsámicos sobre nuestro pasado. Este, con suma probabilidad, es uno de los apartados más controvertidos de la obra.

En lo que concierne a tal realidad, y como colofón, el historiador nos ofrece un ácido análisis sobre los posicionamientos más críticos con el proceso transicional, muchos de ellos, como el soberanismo catalán o Podemos, alentados por la crisis económica y la sucesiva crisis sociopolítica de lo que interpretan como "el régimen del 78". Para Juliá, esta noción es una quimera, una argucia política que posee la mácula del presentismo y que no captaría ni las dificultades a las que se vio envuelto el proceso ni el devenir de cuarenta años de decisiones políticas en democracia, un debate cuyas ascuas siguen crepitando tras dos años de la publicación de esta obra. En lo conferido a dicha cuestión, quizá la obra precise algo más de detenimiento para desvelar cómo operan los legados históricos que, además, permita integrar a España en otras problemáticas en nuestro entorno más cercano. 
Con estos mimbres, Santos Juliá nos propone una obra extensa, cargada de fuentes y matices. Una vasta historia de la política española que muestra que los usos públicos de nuestra historia siguen latentes, que la Transición sigue ostentando "buena salud".

Miguel C. Padrón Alemán

Universidad de Zaragoza

miguelpadron@unizar.es

Fecha de recepción: 14 de junio de 2019

Fecha de aceptación: 22 de junio de 2019

Publicación: 30 de junio de 2019

$\underline{\text { Para citar este artículo: }}$

Miguel C. Padrón, "Santos Juliá, La Transición. Historia de una política española (19372017). Madrid: Galaxia Gutenberg, 2017, 656 págs.", Historiografias, 17 (enero-junio, 2019): pp. 171-174. 